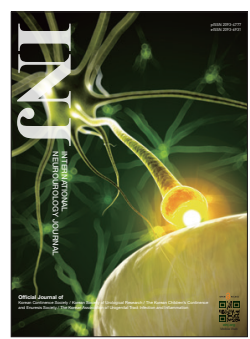

\title{
What Is Fecal Incontinence That Urologists Need to Know?
}

\author{
Hongwook Kim ${ }^{1,2}$, Jisung Shim ${ }^{3}$, Yumi Seo ${ }^{4}$, Changho Lee ${ }^{5}$, Youngseop Chang ${ }^{1}$ \\ ${ }^{1}$ Department of Urology, Konyang University College of Medicine, Daejeon, Korea \\ ${ }^{2}$ Konyang University Myunggok Medical Research Institute, Daejeon, Korea \\ ${ }^{3}$ Department of Urology, Korea University College of Medicine, Seoul, Korea \\ ${ }^{4}$ Department of Urology, Dankook University College of Medicine, Cheonan, Korea \\ ${ }^{5}$ Department of Urology, Soonchunhyang University College of Medicine, Cheonan, Korea
}

Fecal incontinence (FI) undoubtedly reduces quality of life and adversely affects the social life of the affected individual. FI has a higher prevalence with age and has an equivalent prevalence to urinary incontinence in patients with genitourinary disease, but is often not confirmed in these cases. A thorough investigation is needed to diagnose FI, with the common etiology of this condition in mind, and several questionnaires can be used to identify symptoms. The physical examination contains digital rectal examination carries out to identify the patient's condition. Ultrasound, colonoscopy, and rectum pressure test can be performed. Patients educated in diet-related issues, bowel movements, and defecation mechanism. Nonoperative options such as diet control and Kegel exercise should be performed at first. Surgical treatment of FI is considered when conservative management and oral medications produce no improvement. Surgical options include less invasive procedures like bulking agent injections, and more involved approaches from sacral nerve stimulation to invasive direct sphincter repair and artificial bowel sphincter insertion. Good outcomes in FI cases have also recently been reported for barrier devices.

Keywords: Fecal incontinence; Graciloplasty; Sacral nerve stimulation; Sphincteroplasty

- Conflict of Interest: No potential conflict of interest relevant to this article was reported.

\section{DEFINITION}

Fecal incontinence (FI) is defined as repeated, uncontrolled excretion of feces over a minimum of 3 months [1]. Clear mucus secretion should be excluded by careful questioning of the patient. Gas incontinence is often included in the definition of FI but is not included in its current diagnosis because it is difficult to define when the gas passage is abnormal. FI typically involves diarrhea, impaired bowel storage capacity, and a weakening of the pelvic floor $[1,2]$ (Table 1). FI is usually considered abnormal after about 4 years of age once toilet training has been completed [3].

\section{Diagnostic Criteria for FI}

FI is defined as a recurrent uncontrolled passage of fecal material over the prior 3 months in an individual with a developmental age of at least 4 years [1]. For research studies of this disorder, it is recommended that the onset of symptoms be considered for at least 6 months previously and confirmed cases should undergo 2-4 episodes of FI over any 4-week period.

\section{Prevalence}

Several community-based large-scale studies in the United States have suggested that FI is common, with a prevalence ranging from $7 \%$ to $15 \%$ in community-dwelling women, $18 \%$ to $33 \%$ in hospitals, and $50 \%$ to $70 \%$ in nursing homes $[4,5]$.
Corresponding author: Youngseop Chang (iD https://orcid.org/0000-0002-3938-0050 Department of Urology, Konyang Univeristy, School of Medicine, Konyang University Hospital, 158 Gwanjeodong-ro, Seo-gu, Daejeon 35365, Korea Email: urolapa@kyuh.ac.kr

Submitted: June 30, 2020 / Accepted after revision: October 26, 2020
This is an Open Access article distributed under the terms of the Creative Commons Attribution Non-Commercial License (https://creativecommons.org/licenses/by-nc/4.0/) which permits unrestricted non-commercial use, distribution, and reproduction in any medium, provided the original work is properly cited. 
Table 1. Common causes of fecal incontinence

\begin{tabular}{l} 
Anal sphincter weakness \\
Traumatic: obstetric, surgical (e.g., hemorrhoidectomy, internal \\
sphincterotomy, fistulectomy) \\
Nontraumatic: scleroderma, idiopathic internal sphincter \\
degeneration \\
Neuropathy \\
Peripheral (e.g., pudendal) or generalized (e.g., diabetes mellitus) \\
Pelvic floor disorders \\
Rectal prolapse, descending perineum syndrome \\
Disorders affecting rectal capacity and/or sensation ${ }^{\text {a) }}$ \\
Inflammatory conditions: radiation proctitis, Crohn disease, \\
ulcerative colitis \\
Anorectal surgery (pouch, anterior resection) \\
Rectal hyposensitivity \\
Rectal hypersensitivity \\
Central nervous system disorders \\
Dementia, stroke, brain tumors, multiple sclerosis, spinal cord lesions \\
Psychiatric diseases, behavioral disorders \\
Bowel disturbances \\
Irritable bowel syndrome, postcholecystectomy diarrhea \\
Constipation and fecal retention with overflow \\
\hline
\end{tabular}

a)These conditions may also be associated with diarrhea.

The FI prevalence is generally found to be similar or lower in men than in women [2,6,7]. Interestingly, most FI patients seen in the clinic are women. In Korea, large-scale studies are rare. Among those that have been conducted, the incidence of incontinence in adult Korean was reported at $6.4 \%$ with a higher frequency in individuals over 50 years of age [8]. Another Korean study has described a FI prevalence of community-dwelling people aged 60 and older was $15.5 \%$ [9]. It should be noted that FI prevalence can be affected by population characteristics and statistical data, and by differences in definition, survey methods, screening questions, and differences in the reference time frame (e.g., 1 year or prior month) [2,10].

\section{Etiology}

The etiology of FI is multifactorial $[1,9]$. It is thus more appropriate to focus on the relationship between the associated conditions and risk factors for this disorder, especially prior to its onset. In community surveys of bowel disturbances, particularly diarrhea and those involving rectal urgency, the burden of chronic disease was a more important and independent risk factor for FI than obstetric-related pelvic injuries (e.g., forceps, complicated episiotomy) $[2,11,12]$. An older age, watery diarrhea, and functional diarrhea have been identified as independent predictors in the Korean population [8]. Diabetes can also contribute to FI by weakening the sphincter or pelvic floor via anatomical defects, nerve damage or microvascular complications, and increases the risk of this disease in older women $[13,14]$.

In a prior study of a community-based cohort, current smoking, body mass index, diarrhea, irritable bowel syndrome, cholecystectomy, and rectal prolapse were found to be independent risk factors for FI, with cholecystectomy and smoking observed to be more relevant than obesity [12]. Smoking, external sphincter atrophy, and obesity are also reported risk factors for FI $[13,15]$. Other conditions associated with FI include age, disease burden (number of accompanying events, diabetes), anal sphincter trauma (obstetric injury, prior surgery), and reduced physical activity [12-14]. Anorectal sensorimotor dysfunctions and/or altered bowel habits are also associated with FI in clinical practice (Table 1). Some of these conditions have not appeared to be a risk factor in community studies, which may be due to their relatively low prevalence. Consistent with the results of community-based studies, the majority of women with FI who consult physicians may not have a nervous system or inflammatory disorder but may have bowel disturbance disorders (usually diarrhea) associated with a history of obstetric risk factors. Notably however, neurological deficits can be identified only by neurophysiological tests which are not widely available. In a series of studies, the incidence of FI after vaginal delivery was less than $10 \%$. There was no obvious difference between cesarean section and vaginal delivery. This may reflect a reduction in the use of vaginal delivery devices (e.g., forceps), a decrease in episiotomy procedures, and changes to cesarean delivery protocols $[16,17]$. The risk of FI is higher in women who undergo device-assisted deliveries, but whether or not the obstetric damage affects FI is not clear [12,15].

Anorectal surgery for a fistula, fissure, hemorrhoids, or resection of an anorectal carcinoma can damage the sphincter. In addition, impaired rectal compliance, as can occur following proctitis or after the creation of a pouch, and fecal impaction with diarrhea overflow can all cause FI [1].

\section{Impact on quality of life and psychological factors}

Individuals affected by FI all report social life impacts. Coexisting psychological problems can include anxiety and depression, low self-esteem, and sexual problems $[11,18]$. Quality of life (QoL) and FI symptoms can be assessed by questionnaires and 
a significant correlation has been found between symptom severity and QoL in FI patients [19].

\section{Pathophysiology \\ Physiological factors}

Continence is maintained by several mechanisms, including anatomical structures (endovascular cushions, the integrity of the anal sphincter, and the puborectalis muscle), rectoanal sensation, rectal compliance, neuronal innervation, stool consistency, mobility, and psychological factors [20]. FI occurs when the normal anatomy or physiology that maintain the structure and function of the anorectal unit are disrupted [21].

\section{Anorectal and pelvic floor musculature}

Anal sphincter weakness and rectal sensory disturbances contribute to FI. Approximately $40 \%$ of older women with FI show reduced anal resting pressure and $80 \%$ have reduced squeeze pressure $[20,22]$. Internal anal sphincter (IAS) dysfunction is characterized by exaggerated spontaneous relaxation of the IAS or decreased resting pressure. This condition is associated with structural disturbances i.e., defects (after obstetric injury) and/ or thinning (scleroderma, old age). Among postpartum women, the severity of FI is greater in cases involving IAS defects [23]. The weakening of the external anal sphincter (EAS) may be caused by one or more of the following factors: an impaired sphincter, neuropathy, myopathy, or decreased corticospinal input. In addition to the anal sphincter, levator ani muscles also contribute to the pelvic barrier. According to one study, the reduction of inward traction by the puborectalis in FI patients was more closely correlated with symptoms than when pressure was applied.

Because of differences in muscle mass and obstetric injury, women show greater anal sphincter dysfunction than men among cases with FI. Unlike women with FI, men with this condition often have no sphincter defects and it has arisen in these male cases due to an iatrogenic anal injury (e.g., following a perianal procedure), a long anal sphincter with abnormally high resting tone, or as a result of radiation therapy [24-26].

\section{Rectal compliance and rectoanal sensation}

Rectal distention due to bowel movements is associated with several processes that help to preserve continence or, when appropriate, excretion. Rectal distention induces a reflex relaxation of the IAS and is recognized as a fullness of the work as if the rectum was uncomfortably full of gas or feces. If excretion is uncomfortable, the desire to defecate promotes the spontaneous contraction of the external sphincter and puborectalis muscle, which makes the tension and stool more tolerable. There is a close correlation between rectal sense and EAS contraction, which indicates that EAS delay or lack of contraction may result in FI [27].

Sphincter pressure alone cannot always distinguish between the presence or absence of incontinence. Reduced rectal sensation may allow feces to enter the anal canal and perhaps leak before the external sphincter contracts. Reducing rectal sensitivity and increasing rectal compliance can contribute to fecal retention by decreasing the frequency and intensity of excrement. Conversely, preservation of the stool can reduce rectal sensation by affecting the condition of the rectum and the afferent nerve pathways [1].

Rectal hypersensitivity may be associated with a reduction in rectal compliance and repetitive contraction of the rectum during rectal distention. Rectal capacity is reduced in women with FI and is associated with symptoms of urgency $[20,22]$. In addition, rectal hypersensitivity cannot be fully explained by disturbances in rectal compliance alone. Anal sphincter relaxation may also occur with contractions that can detect whether the contents of the rectum are gas, liquid, or feces. In incontinence, the urinary frequency is reduced and the sensory information seems to be lost. In addition to anorectal dysfunctions, continence can also be affected by impaired fecal concentration and/ or transmission disturbances, impaired mental faculties, and mobility. These observations confirm that FI is a heterogeneous disorder and that patients often show one or more deficits.

\section{Fecal Incontinence: Diagnosis and Workup History taking}

To manage FI in the clinic, a specific medical history must be obtained and clinicians should conduct such inquiries with care and diligence because patients are likely to be uncomfortable when discussing symptoms of incontinence. History taking should include the frequency of FI, severity of symptoms and contents and effects of FI on a patient's QoL. Individuals will typically change their social and occupational patterns due to the onset of FI. A focus by clinicians on only the frequency and type of FI is may thus overlook the effects of this condition on QoL.

FI patients are likely to be reluctant to actively discuss their symptoms. According to a cross-sectional study by Dunivan et al. [28], 36.2\% of patients present with FI. However, only 2.7\% 
are diagnosed medically with this disorder. Older patients must be assessed for FI onset because age and intestinal diseases that cause diarrhea are significant risk factors for this condition $[2,7,29]$. Moreover, the Bristol stool form scale can be used to assess the consistency of the stool as two-thirds of patients who complain of FI will have a soft stool.

Several studies have recommended that clinicians should be sensitive when discussing different issues related to FI [30-32], including the most uncomfortable aspects of this disorder, how they affect the patient's life, the factors that cause or worsen the condition, and the period in which the symptoms developed. A patient's previous examinations, treatments, and reactions should be cautiously documented. Moreover, information about spinal surgery, comorbidities (diabetes, stroke, and chemotherapy), and current medications must be obtained.

\section{Symptom Analysis}

A key symptom of FI is the loss of restraint in relation to various contents of the rectum i.e., solid stool, liquid/semi-formed stool, and gas. The outcomes of FI can be generally classified as staining, soilage, seepage, and accidents. Treatments may be changed due to pelvic floor disorders, rectal surgery, radiation therapy, hemorrhoid protrusion, and iatrogenic anal injury [29] but it is important also to distinguish between FI subtypes. FI without any awareness is referred to as passive FI, and leakage with self-awareness despite a positive measure is referred to as urge FI. In the former case, the FI correlates with sensory impairment, rectoanal reflex disorder, or abnormal function of the anal sphincter. The latter indicates that the sphincter has an abnormal function, or the rectum has a decreased capacity. Stool leaking after defecation may occur if the stool is incompletely discharged or rectal sensation is impaired.

\section{Questionnaires}

The extent of symptoms in FI cases should be quantified using one of the validated scoring systems. Several measurement tools of proven efficacy for assessing the severity of symptoms and analyzing the effects of FI have been introduced [33,34]. However, this type of assessment is complicated by a striking absence of standardized definitions and of instruments that can be used to measure and quantitate FI. Although numerous scoring systems are commonly used (e.g., the Wexner/Cleveland Clinic Florida incontinence score, Fecal Incontinence Quality of Life questionnaire, Fecal Incontinence Severity Index, and St. Marks incontinence score) [33], none include physiologic com- ponents or objective test parameters that can accurately reflect the clinical severity of FI. Instead, most instruments are based on a subjective patient-reported assessment of severity and frequency.

\section{Physical Examinations}

Because FI can be caused by systemic or neurological diseases, both physical and neurological examinations should be performed.

\section{Visual inspection}

Physical examinations include visual observations around the anus, rectal digital examinations, and cautious assessment of the perineum. The left lateral position is the best position for assessing the perineum and conducting a rectal examination $[35,36]$. Chronic skin irritation due to stool leakage can be identified via visual inspection and assessment of feces around the anus, protruding hemorrhoids, dermatitis or scars around the anus, and a patulous anus. In addition, the patient can squat to provide strength and excessive perineum descent (more than $3 \mathrm{~cm}$ ) or to assess rectal escape. Tapping the perianal skin lightly with a cotton swab causes normal contraction of the EAS. If there is loss of anal skin reflexes, the afferent or efferent nerve cells may be damaged [36]. Notably, the second symptom is leakage of stools, which can cause pruritus, perianal skin irritation, or urinary tract infections. Some patients present more commonly with secondary symptoms rather than FI itself.

\section{Digital rectal examinations}

Rectal examinations should be performed by experienced clinicians. The integrity of the sphincter, pressure of the sphincter during the resting phase, contractile force of the external sphincter, contractile force of the puborectalis muscle, degree of perineal descending, length of the anal canal, rectocele, fecal impaction, or mass should be assessed [36]. In one prior study, experienced clinicians have reported positive predictive values of $67 \%$ and $81 \%$ for low resting pressure and increased abdominal pressure, respectively, based on digital rectal examinations. Moreover, Tantiphlachiva et al. [37] have found that rectal digital examinations have a high sensitivity and specificity in determining whether the pelvic floor has normal function.

\section{Assessment of FI}

If there is uncertainty in the diagnosis of FI after history taking and physical examination, and when several factors - such as 
Table 2. Workup for the diagnosis of fecal incontinence in adults

To evaluate anorectal structure and function
Anorectal examination
Pelvic MRI ${ }^{\mathrm{a}}$ )
Barium defecography ${ }^{\mathrm{b})}$
To evaluate anorectal structure only
Anal sonography ${ }^{\mathrm{b})}$
To evaluate anorectal function only
Anorectal manometry ${ }^{\mathrm{c})}$
EMG of the puborectalis and external anal sphincter muscles ${ }^{\mathrm{d})}$
Pudendal-nerve terminal motor latency ${ }^{\mathrm{e}}$
a) Pelvic magnetic resonance imaging (MRI) is not widely available. ${ }^{\mathrm{b})}$ This
test is used when surgery is contemplated. However, it is not available.
c) Anorectal manometry is most useful when an experienced examiner is
not available or when the data obtained via history taking and physical ex-
amination are not validated. ${ }^{d}$ Electromyography is performed when sur-
gery is contemplated and a defect in the external anal sphincter is detected.
e) Pudendal-nerve terminal motor latency is performed when surgery is
contemplated and an expert clinician who performs EMG is not available.
Adapted from Wald. New Eng J Med 2007;356:1648-55, with permission
of NEJM [70].

overflow incontinence, decreased rectal capacity, and FI due to neurological causes - are excluded, further tests can be performed to analyze the structure and function of the anorectal lesion (Table 2).

\section{Flexible Sigmoidoscopy/Colonoscopy}

Endoscopic evaluation of the rectosigmoid region is recommended to rule out colonic mucosal inflammation, rectal mass, or stricture, which can be achieved by performing flexible sigmoidoscopy. However, a colonoscopy may be more appropriate, particularly in an older individual. If patients have FI with diarrhea, endoscopic examination should be conducted to rule out inflammation of the mucous membranes, tumors, or narrowing of the rectum. Blood tests are then recommended to assess for thyroid function or other metabolic diseases as well as stool analysis.

\section{Endoanal Sonography}

Endoanal sonography is widely used as it is the most sensitive test for assessing sphincter defects or structural changes. Moreover, it can identify the thickness and structural deformities of the EAS and IAS [38] and is effective in detecting the rectal wall and puborectalis muscle. In particular, the endoanal sonography findings for an anal sphincter deformity have been found to be in good agreement with those from anorectal manometry [39]. EAS defects are detected with extremely high accuracy with this methodology. Sultan et al. [40] have used this technique to show that about $35 \%$ of parous women have defects in the EAS. If rectification of the sphincter injury is considered, sonography is particularly useful for identifying the structure of the sphincter. If sphincter injury is then found, evaluation of the EAS and electromyography of the puborectalis muscle can be helpful because they can rule out any accompanying denervation (a condition which decreases the surgical success rate in the experience of many clinicians).

\section{Anorectal Manometry}

Anorectal manometry and rectal sensory tests are effective in determining the function of the EAS/IAS and rectal sensory abnormalities. Prior studies have aimed to identify the rectal muscle strength as a reservoir through an objective understanding of the anorectal sensation, degree of endurance to stool volume, and rectal compliance [41-44]. Moreover, anal pressure measurement can be useful for biofeedback therapy $[45,46]$. In general, rest pressure, compression pressure, rectal sensation, rectal-anal reflex, and rectal compliance of the anal sphincter are measured (Fig. 1). Patients with FI have low anal sphincter pressure or decreased rectal sensations.

Anorectal manometry tests the magnitude of the resting anal pressure at a high-pressure zone (85\% coming from rhythmic slow wave contractions of the IAS and 15\% from tonic contraction of the EAS). The most common method is the use of a water-perfused catheter containing 4 recording channels to detect pressure at various points along the rectum/anal canal, with a balloon at the end. After testing baseline resting pressures, the patient is instructed to cough and then to squeeze the EAS, which provides the voluntary squeeze pressure. The pressures should increase quickly to prevent incontinence. The rectal balloon is then distended with fluid to elicit a quick decrease in anal pressure, indicating competency of the sampling reflex.

\section{Electromyography}

Electromyography is another method that can be used to detect nerve damage. Because denervation of a skeletal muscle is accompanied by re-innervation from neighboring axons, a singlefiber EMG electrode can detect multiple axons firing within a small area of the muscle to indicate whether it has been damaged and re-innervation has occurred. 

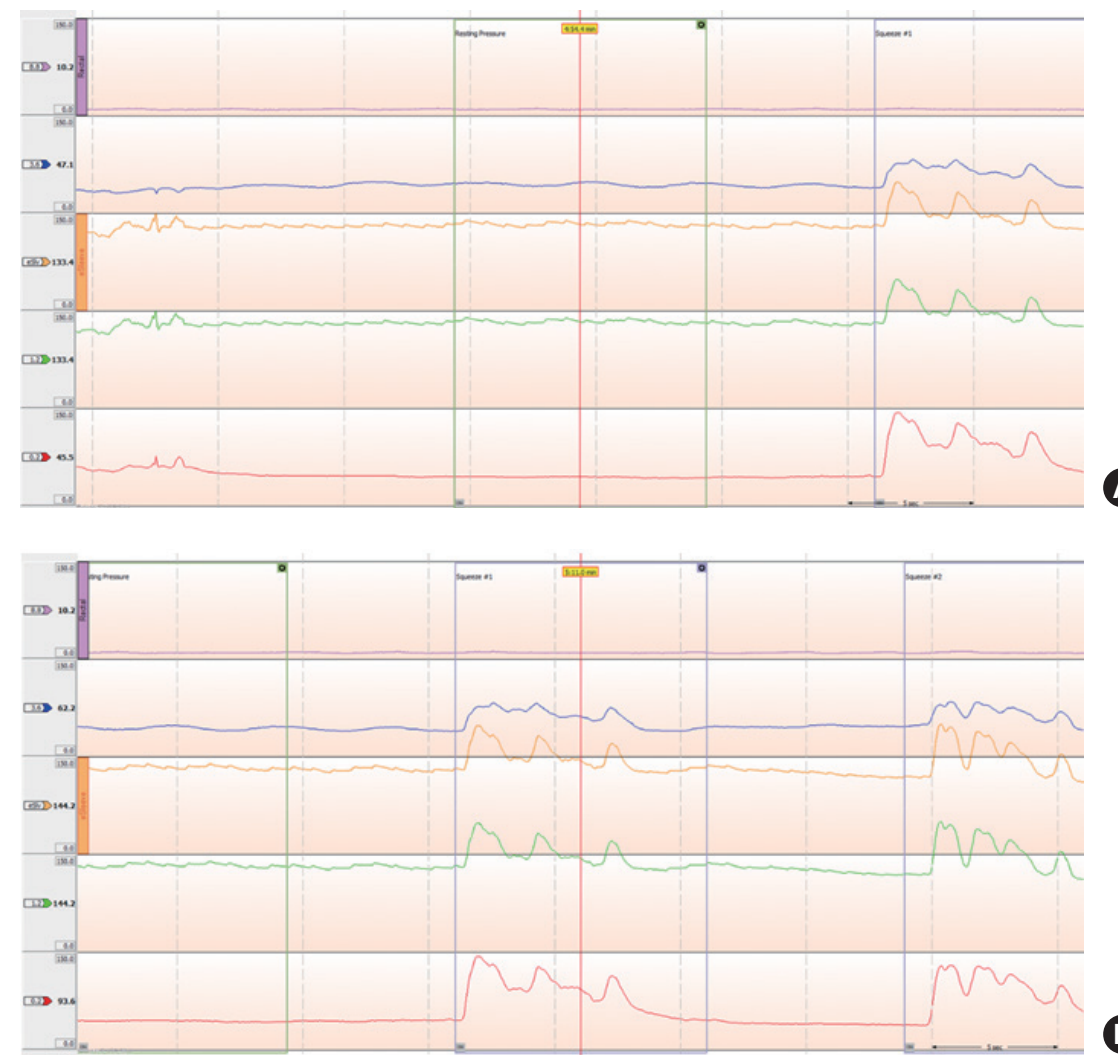

B

Fig. 1. Manometric pressure profiles during catheter withdrawal demonstrating normal rest (A) and squeeze profiles (B).

\section{Radiologic Testing}

Magnetic resonance imaging (MRI) of the anus or rectum has been recommended as an effective method for identifying the EAS, rectum, or structure around the rectum [47]. Among the types of MRI, dynamic MRI can provide good information about the anatomy and function of the pelvic floor but is not widely used as it is not cost-effective. Other possible tests may include changes in the anorectal angle, descent of the pelvic floor, length of the anal tube, rectocele, rectal prolapse, and rectal intussusception.

\section{Medical Interventions}

The initial treatment of FI is to educate the patient about the bowel function and the disease. By allowing patients to better understand FI, they can increase the effectiveness of their treatment and improve compliance. Although there is not yet enough evidence to show the effects of lift style modifications on FI, they are still recommended. Weight reduction also seems to be effective because obesity is a risk factor in FI as mentioned above, although no relationship between weight reduction and an FI decrease has been reported. A relative FI risk reduction of
$20 \%(\mathrm{P}=0.29)$ has been reported after bariatric surgery [48]. To prevent FI, it is also important to maintain regular bowel movements and defecation times and processed foods are not recommended. Patients are also recommended to keep a daily food diary to determine whether certain foods exacerbate FI symptoms. Bananas and potatoes are known to be helpful for loose stools and the intake of water within 30 minutes after meals can promote the movement of food in the intestines. However, this can promote food passage and worsen FI. It is thus recommended to wait for 30 minutes after eating before drinking. Many FI patients take laxatives due to constipation but this will prevent a constant stool. Augmented fluid intake and fiber-rich foods will typically improve constipation. A previous prospective study in older women reported that increased long-term dietary fiber intake decreased the risk of FI but other dietary treatments showed no significant effect [49].

As with urinary incontinence, Kegel exercises can help with FI. Pelvic floor muscle exercises after colo-anal anastomosis can improve FI symptoms and related QoL levels in colorectal cancer patients [50]. Kegel exercises can also prevent urinary and fecal incontinence in antenatal and postnatal women [51]. 
Bowel movement modification treatments include biofeedback treatment and a retraining program, which involves relearning by patients to assist with regular, effective and complete bowel movements. This can be done by inserting instruments or balloons with an electric sensor into the anus to strengthen the anal muscles. This procedure is used also to restore the sensation of the rectum [52]. The success rate of biofeedback treatments are reported to be 50\%-90\% [53]. However, if the pelvic floor is totally denervated or the capacity of the rectum is reduced due to surgery, the patient may be unresponsive.

Antimotility agents should be administered if intestinal motility is increased and incontinence occurs, and caffeine, alcohol, milk, and carbonated drinks should be avoided as much as possible. It is important to achieve a regular and predictable pattern of bowel movements. Complete emptying of the rectum is the best approach to preventing FI and this can be assisted by increasing dietary fiber intake, enemas or by stimulating the rectum [49]. Loperamide may be effective in diarrhea-related FI patients [54]. Small-scale trials, have also found that loperamide decreases FI symptoms. Loperamide and psyllium have both been found to reduce FI symptom severity but the loperamide group experienced more constipation (29\% vs. $10 \%)$ [55].

\section{Surgical Procedures \\ Direct repair of sphincter defects and augmentation of the sphincter}

Open surgical treatments for FI can be divided into 2 major categories: direct repair of the sphincter defect and augmentation of the sphincter. Secondary sphincter defects due to obstetric trauma or iatrogenic damage are appropriate for direct reduction of the sphincter. There are 3 main approaches to this direct repair: apposition, overlapping, and plication or reefing [56]. If adequate sphincters are present, overlapping is the preferred method. When the external sphincter or puborectalis is used in a wrinkle method, the wrinkle is made to narrow the opening toward the middle of the anus [56]. However, there have been few reports to date on direct sphincter repair, and the results have not been satisfactory in long-term studies. Moreover, the rate of wound infections following this procedure is reported to be $6 \%-35 \%$ [57].

\section{Graciloplasty}

The Gracilis muscle transposition method is one of the many ways to strengthen the sphincter. In this procedure, the Gracilis muscle is tunneled to the perineum to enclose the anal sphincter [58]. Dynamic graciloplasty is another approach in which an electrode is connected and the success rate is reported to be $40 \%-80 \%$ [59]. This method can be applied to young patients who have had a failed sphincter repair or have severe defects or intense sphincter deficiency such as congenital deficiency. However, this surgery is not recommended in FI cases with chronic diarrhea, irritable bowel syndrome, difficult to treat constipation, or anal disease [56]. Similar surgical approaches using the gluteus maximus have also been reported.

\section{Bulking agents}

Biocompatible bulking agents given by periurethral injection have been used successfully to treat incontinence. The bulking agents are used to reinforce the walls of the IAS to close the anal canal. They also raise the pressure inside the perianal area and thereby alleviate FI symptoms. Many agents are used in these injections including fats, Teflon, and dextranomer microspheres in nonanimal stabilized hyaluronic acid (NASHA Dx). NASHA Dx was found previously in a randomized, doubleblind sham-controlled study to be effective in $52 \%$ of the treatment subjects at 6 months [60].

\section{Stem cell injection}

Stem cell therapy is a recently introduced treatment for FI $[61,62]$ and has been tested in many other clinical fields such as knee disease, hair loss, dementia, and urinary incontinence. A recent phase 2 randomized, double-blind, placebo-controlled study of intrasphincteric injections of autologous myoblasts was conducted in $24 \mathrm{FI}$ patients. A higher response rate in the treated group than in the placebo group was reported at 12 months ( $58 \%$ vs. $8 \%, \mathrm{P}=0.03$ ) [63]. Adverse events in 3 cases were described, including transient pain at the biopsy site $(\mathrm{n}=2)$ and 1 cutaneous infection at the biopsy site that was treated successfully with antibiotics $(n=1)$, but none were serious and all resolved quickly. There were no significant differences relative to baseline found in the autologous myoblast group in terms of anorectal electrophysiology, ultrasonography, electrophysiological testing, or MRI. The mechanism by which the FI symptoms improved is not yet clear and requires further research.

\section{Sacral nerve stimulation}

Sacral nerve stimulation (SNS) is indicated in patients with neurogenic anomalies with either a normal anal sphincter or with a sphincter correction failure [64]. In this procedure, SNS 
electrodes are inserted through the S3 foramen to stimulate the anus and pelvic floor. If the frequency of incontinence decreases by more than $50 \%$ over a test period of about $2-3$ weeks, the electrode is inserted permanently. If there are no complications, the electrode can be maintained for about 8 years. Although the precise mechanism by which SNS works is not yet known, it has low side effects and high efficacy. Although the trials of SNS to date have typically involved only small numbers of cases, the advantage of this procedure is that it is familiar to urologists.

\section{Artificial bowel sphincter}

An artificial bowel sphincter is sometimes used to correct FI, and consists of a controlled cuff filled with a fluid that is wrapped around the anus. An inflated balloon controls the incontinence and stool discharge occurs when the balloon contracts. This treatment can be applied in cases of severe FI that have not improved following standard therapy or have had a

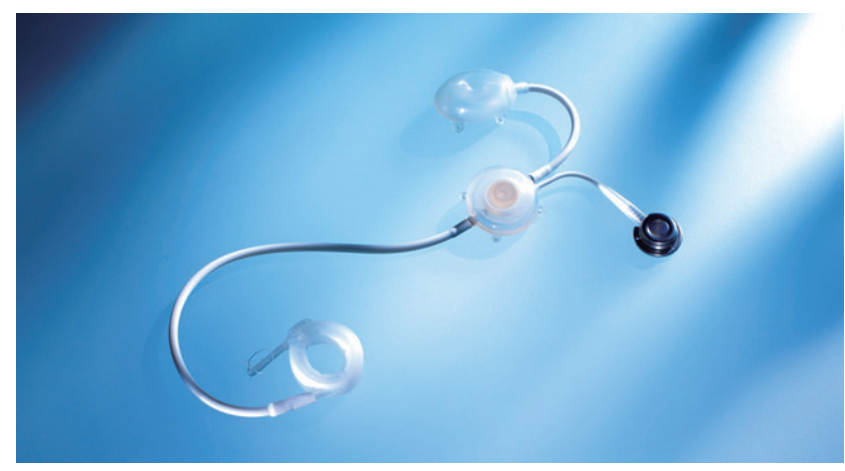

Fig. 2. A.M.I. Soft Anal Band (Agency for Medical Innovations; A.M.I. Feldkirch Austria). Adapted from www.ami.at, with permission of A.M.I.

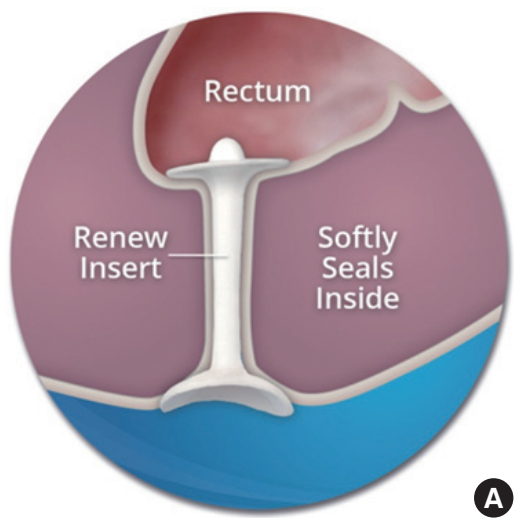

previous failed surgery. In addition, if the surgical wound is not recovering well, local anal disease, diarrhea, and untreated constipation can be avoided using this device. Notably however, the risk of side effects from the use of an artificial bowel sphincter, including infection and erosion, are high [56]. The soft anal band $^{\oplus}$ from A.M.I. (Feldkirch, Austria) is a device similar to an artificial bowel sphincter (Fig. 2). It has a high incidence of complications, but significantly improves fecal incontinence [65]. An anal sphincter using a magnet has also been reported, which has advantages over an artificial intestinal sphincter. In $57 \%$ of patients that received this version of an artificial sphincter, the incidence of FI decreased by more than half, but complications such as infection and erosion occurred in $20 \%$ of cases [66].

\section{Barrier device}

A barrier device has been developed that mechanically blocks incontinence via anal occlusion using a plug but previous studies of this approach have reported a low satisfaction rate [67]. However, a recent report indicated an incontinence improvement of more than $50 \%$ in $62 \%$ of FI patients who received a barrier device and a high satisfaction rate of 78\% [68] (Fig. 3).

\section{Fecal diversion}

Fecal diversion is an effective and safe method to consider upon FI treatment failure. Colostomy or ileostomy can be considered when there is severe neurogenic FI, complete pelvic nerve block, severe perianal injury, or severe radiation incontinence [69]. These approaches have significant QoL drawbacks with considerable mental and social effects.

Fig. 3. The Barrier device. (A) Renew insert, (B) applicator. Adapted from https://renew-medical.uk/products/renew-insert/, with permission of Renew Medical UK. 


\section{CONCLUSIONS}

FI is a very severe disease that causes a lot of stress for the affected patient. Its incidence increases with age and it may be one of the most common unmet needs among patients visiting a urology clinic. It is thus important to thoroughly evaluate urology patients to identify possible FI symptoms including physical examinations, and to then determine the most appropriate treatment. Common causes of FI such as diarrhea or constipation should be identified at the beginning and treated appropriately to prevent more severe interventions that may be unnecessary. Treatments, from conservative to invasive approaches, need to be tailored to the individual patient.

\section{AUTHOR ORCID}

$\begin{array}{ll}\text { Hongwook Kim } & 0000-0002-3847-1401 \\ \text { Jisung Shim } & 0000-0002-6745-1776 \\ \text { Yumi Seo } & 0000-0001-8027-7170 \\ \text { Changho Lee } & 0000-0003-3189-5532 \\ \text { Youngseop Chang } & 0000-0002-3938-0050\end{array}$

\section{AUTHOR CONTRIBUTION STATEMENT}

- Conceptualization: $\mathrm{CL}$

- Data curation: CL

- Formal analysis: YC

- Methodology: JS

- Project administration: YC

- Visualization: YS, YC

-Writing - original draft: HK, JS, YS

-Writing - review \& editing: HK, CL

\section{REFERENCES}

1. Rao SS, Bharucha AE, Chiarioni G, Felt-Bersma R, Knowles C, Malcolm A, et al. Anorectal disorders. Gastroenterology 2016;150: 1430-42.e4.

2. Whitehead WE, Borrud L, Goode PS, Meikle S, Mueller ER, Tuteja A, et al. Fecal incontinence in US adults: epidemiology and risk factors. Gastroenterology 2009;137:512-7.e2.

3. Bongers ME, Benninga MA. Functional fecal incontinence in children. Annales Nestlé (English ed) 2007;65:81-8.

4. Nelson R, Furner S, Jesudason V. Fecal incontinence in Wisconsin nursing homes: prevalence and associations. Dis Colon Rectum
1998;41:1226-9.

5. Bliss DZ, Harms S, Garrard JM, Cunanan K, Savik K, Gurvich O, et al. Prevalence of incontinence by race and ethnicity of older people admitted to nursing homes. J Am Med Dir Assoc 2013;14:451. e1-7.

6. Perry S, Shaw C, McGrother C, Matthews R, Assassa R, Dallosso H, et al. Prevalence of faecal incontinence in adults aged 40 years or more living in the community. Gut 2002;50:480-4.

7. Ditah I, Devaki P, Luma HN, Ditah C, Njei B, Jaiyeoba C, et al. Prevalence, trends, and risk factors for fecal incontinence in United States adults, 2005-2010. Clin Gastroenterol Hepatol 2014;12:63643.e2.

8. Kang HW, Jung HK, Kwon KJ, Song EM, Choi JY, Kim SE, et al. Prevalence and predictive factors of fecal incontinence. J Neurogastroenterol Motil 2012;18:86-93.

9. Joh HK, Seong MK, Oh SW. Fecal incontinence in elderly Koreans. J Am Geriatr Soc 2010;58:116-21.

10. Ng KS, Nassar N, Hamd K, Nagarajah A, Gladman M. Prevalence of functional bowel disorders and faecal incontinence: an Australian primary care survey. Colorectal Dis 2015;17:150-9.

11. Koloski N, Jones M, Kalantar J, Weltman M, Zaguirre J, Talley N. Psychological impact and risk factors associated with new onset fecal incontinence. J Psychosom Res 2012;73:464-8.

12. Bharucha AE, Zinsmeister AR, Schleck CD, Melton III LJ. Bowel disturbances are the most important risk factors for late onset fecal incontinence: a population-based case-control study in women. Gastroenterology 2010;139:1559-66.

13. Matthews CA, Whitehead WE, Townsend MK, Grodstein F. Risk factors for urinary, fecal or dual incontinence in the Nurses' Health Study. Obstet Gynecol 2013;122:539-45.

14. Bharucha AE, Dunivan G, Goode PS, Lukacz ES, Markland AD, Matthews CA, et al. Epidemiology, pathophysiology, and classification of fecal incontinence: state of the science summary for the $\mathrm{Na}$ tional Institute of Diabetes and Digestive and Kidney Diseases (NIDDK) workshop. Am J Gastroenterol 2015;110:127-36.

15. MacLennan AH, Taylor AW, Wilson DH, Wilson D. The prevalence of pelvic floor disorders and their relationship to gender, age, parity and mode of delivery. BJOG 2000;107:1460-70.

16. Rogers R, Leeman L, Borders N, Qualls C, Fullilove AM, Teaf D, et al. Contribution of the second stage of labour to pelvic floor dysfunction: a prospective cohort comparison of nulliparous women. BJOG 2014;121:1145-54.

17. Nelson RL, Furner SE, Westercamp M, Farquhar C. Cesarean delivery for the prevention of anal incontinence. Cochrane Database Syst Rev 2010;2010:CD006756. 
18. Visscher A, Lam T, Hart N, Felt-Bersma R. Fecal incontinence, sexual complaints, and anorectal function after third-degree obstetric anal sphincter injury (OASI): 5-year follow-up. Int Urogynecol J 2014;25:607-13.

19. Melville JL, Fan MY, Newton K, Fenner D. Fecal incontinence in US women: a population-based study. Am J Obstet Gynecol 2005;193:2071-6.

20. Sun W, Donnelly T, Read N. Utility of a combined test of anorectal manometry, electromyography, and sensation in determining the mechanism of idiopathic'faecal incontinence. Gut 1992;33:807-13.

21. Rao SS. Pathophysiology of adult fecal incontinence. Gastroenterology 2004;126:S14-22.

22. Bharucha AE, Fletcher JG, Harper C, Hough D, Daube J, Stevens C, et al. Relationship between symptoms and disordered continence mechanisms in women with idiopathic faecal incontinence. Gut 2005;54:546-55.

23. Richter HE, Fielding JR, Bradley CS, Handa VL, Fine P, FitzGerald MP, et al. Endoanal ultrasound findings and fecal incontinence symptoms in women with and without recognized anal sphincter tears. Obstet Gynecol 2006;108:1394-401.

24. Chen H, Humphreys MS, Kettlewell MG, Bulkley GB, Mortensen $\mathrm{N}$, George BD. Anal ultrasound predicts the response to nonoperative treatment of fecal incontinence in men. Ann Surg 1999;229: 739-43.

25. Burgell RE, Bhan C, Lunniss PJ, Scott SM. Fecal incontinence in men: coexistent constipation and impact of rectal hyposensitivity. Dis Colon Rectum 2012;55:18-25.

26. Krol R, Smeenk RJ, van Lin EN, Yeoh EE, Hopman WP. Systematic review: anal and rectal changes after radiotherapy for prostate cancer. Int J Colorectal Dis 2014;29:273-83.

27. Sun W, Read N, Miner P. Relation between rectal sensation and anal function in normal subjects and patients with faecal incontinence. Gut 1990;31:1056-61.

28. Dunivan GC, Heymen S, Palsson OS, von Korff M, Turner MJ, Melville JL, et al. Fecal incontinence in primary care: prevalence, diagnosis, and health care utilization. Am J Obstet Gynecol 2010;202:493.e1-6.

29. Menees SB. My approach to fecal incontinence: it's all about consistency (stool, that is). Am J Gastroenterol 2017;112:977-80.

30. Alavi K, Chan S, Wise P, Kaiser AM, Sudan R, Bordeianou L. Fecal incontinence: etiology, diagnosis, and management. J Gastrointest Surg 2015;19:1910-21.

31. Francone TD. McGraw-Hill Manual: colorectal surgery. Philadelphia (PA): Lippincott Williams and Wilkins; 2009.

32. Paquette IM, Varma MG, Kaiser AM, Steele SR, Rafferty JF. The
American Society of Colon and Rectal Surgeons' clinical practice guideline for the treatment of fecal incontinence. Dis Colon Rectum 2015;58:623-36.

33. Vaizey C, Carapeti E, Cahill J, Kamm M. Prospective comparison of faecal incontinence grading systems. Gut 1999;44:77-80.

34. Vaizey C. Faecal incontinence: standardizing outcome measures. Colorectal Dis 2014;16:156-8.

35. Bharucha AE. Fecal incontinence. Gastroenterology 2003;124: 1672-85.

36. Rao SS. Diagnosis and management of fecal incontinence. American College of Gastroenterology Practice Parameters Committee. Am J Gastroenterol 2004;99:1585-604.

37. Tantiphlachiva K, Rao P, Attaluri A, Rao SS. Digital rectal examination is a useful tool for identifying patients with dyssynergia. Clin Gastroenterol Hepatol 2010;8:955-60.

38. Law P, Kamm M, Bartram C. Anal endosonography in the investigation of faecal incontinence. Br J Surg 1991;78:312-4.

39. Falk P, Blatchford G, Cali R, Christensen M, Thorson A. Transanal ultrasound and manometry in the evaluation of fecal incontinence. Dis Colon Rectum 1994;37:468-72.

40. Sultan AH, Kamm MA, Hudson CN, Thomas JM, Bartram CI. Anal-sphincter disruption during vaginal delivery. New Engl J Med 1993;329:1905-11.

41. Fitzpatrick M, O'Brien C, O'Connell PR, O'Herlihy C. Patterns of abnormal pudendal nerve function that are associated with postpartum fecal incontinence. Am J Obstet Gynecol 2003;189:730-5.

42. Gooneratne ML, Scott SM, Lunniss PJ. Unilateral pudendal neuropathy is common in patients with fecal incontinence. Dis Colon Rectum 2007;50:449-58.

43. Rasmussen OØ, Christiansen J, Tetzschner T, Sørensen M. Pudendal nerve function in idiopathic fecal incontinence. Dis Colon Rectum 2000;43:633-6.

44. Súilleabháin CÓ, Horgan A, McEnroe L, Poon F, Anderson J, Finlay $\mathrm{I}$, et al. The relationship of pudendal nerve terminal motor latency to squeeze pressure in patients with idiopathic fecal incontinence. Dis Colon Rectum 2001;44:666-71.

45. Barnett J, Hasler W, Camilleri M. American Gastroenterological Association medical position statement on anorectal testing techniques. American Gastroenterological Association. Gastroenterology 1999;116:732-60.

46. Bharucha AE. Outcome measures for fecal incontinence: anorectal structure and function. Gastroenterology 2004;126:S90-8.

47. Woodfield CA, Krishnamoorthy S, Hampton BS, Brody JM. Imaging pelvic floor disorders: trend toward comprehensive MRI. Am J Roentgenol 2010;194:1640-9. 
48. Montenegro M, Slongo H, Juliato CRT, Minassian VA, Tavakkoli A, Brito LGO. The Impact of bariatric surgery on pelvic floor dysfunction: a systematic review. J Minim Invasive Gynecol 2019;26:81625.

49. Staller K, Song M, Grodstein F, Whitehead WE, Matthews CA, Kuo B, et al. Increased Long-term dietary fiber intake is associated with a decreased risk of fecal incontinence in older women. Gastroenterology 2018;155:661-7.e1.

50. Hung SL, Lin YH, Yang HY, Kao CC, Tung HY, Wei LH. Pelvic floor muscle exercise for fecal incontinence quality of life after coloanal anastomosis. J Clin Nurs 2016;25:2658-68.

51. Park SH, Kang CB, Jang SY, Kim BY. Effect of Kegel exercise to prevent urinary and fecal incontinence in antenatal and postnatal women: systematic review. J Korean Acad Nurs 2013;43:420-30.

52. Norton C, Cody JD. Biofeedback and/or sphincter exercises for the treatment of faecal incontinence in adults. Cochrane Database Syst Rev 2012;(7):CD002111.

53. Boselli AS, Pinna F, Cecchini S, Costi R, Marchesi F, Violi V, et al. Biofeedback therapy plus anal electrostimulation for fecal incontinence: prognostic factors and effects on anorectal physiology. World J Surg 2010;34:815-21.

54. Sjodahl J, Walter SA, Johansson E, Ingemansson A, Ryn AK, Hallbook O. Combination therapy with biofeedback, loperamide, and stool-bulking agents is effective for the treatment of fecal incontinence in women - a randomized controlled trial. Scand J Gastroenterol 2015;50:965-74.

55. Markland AD, Burgio KL, Whitehead WE, Richter HE, Wilcox $\mathrm{CM}$, Redden DT, et al. Loperamide versus psyllium fiber for treatment of fecal incontinence: the fecal incontinence prescription $(\mathrm{Rx})$ management (FIRM) randomized clinical trial. Dis Colon Rectum 2015;58:983-93.

56. Corman M. Anal incontinence. Colon and rectal surgery. Philadelphia (PA): Lippincott Williams and Wilkins; 2005.

57. Glasgow SC, Lowry AC. Long-term outcomes of anal sphincter repair for fecal incontinence: a systematic review. Dis Colon Rectum 2012;55:482-90.

58. Baeten CG KH. Incontinence. In: Wolff BG, Fleshman JW, Beck DE, Pemberton JH, Wexner SD, editors. The ASCRS textbook of colon and rectal surgery. New York: Springer; 2007. p. 653-64.

59. Chapman AE, Geerdes B, Hewett P, Young J, Eyers T, Kiroff G, et al. Systematic review of dynamic graciloplasty in the treatment of faecal incontinence. Br J Surg 2002;89:138-53.

60. Graf W, Mellgren A, Matzel KE, Hull T, Johansson C, Bernstein M, et al. Efficacy of dextranomer in stabilised hyaluronic acid for treatment of faecal incontinence: a randomised, sham-controlled trial. Lancet 2011;377:997-1003.

61. Kang SB, Lee HN, Lee JY, Park JS, Lee HS, Lee JY. Sphincter contractility after muscle-derived stem cells autograft into the cryoinjured anal sphincters of rats. Dis Colon Rectum 2008;51:1367-73.

62. Frudinger A, Kolle D, Schwaiger W, Pfeifer J, Paede J, Halligan S. Muscle-derived cell injection to treat anal incontinence due to obstetric trauma: pilot study with 1 year follow-up. Gut 2010;59:5561.

63. Boyer O, Bridoux V, Giverne C, Bisson A, Koning E, Leroi AM, et al. Autologous myoblasts for the treatment of fecal incontinence: results of a phase 2 randomized placebo-controlled study (MIAS). Ann Surg 2018;267:443-50.

64. Malouf AJ, Vaizey CJ, Nicholls RJ, Kamm MA. Permanent sacral nerve stimulation for fecal incontinence. Ann Surg 2000;232:143-8.

65. Goos M, Baumgartner U, Lohnert M, Thomusch O, Ruf G. Experience with a new prosthetic anal sphincter in three coloproctological centres. BMC Surg 2013;13:45.

66. Wong MT, Meurette G, Stangherlin P, Lehur PA. The magnetic anal sphincter versus the artificial bowel sphincter: a comparison of 2 treatments for fecal incontinence. Dis Colon Rectum 2011;54: 773-9.

67. Norton C, Kamm MA. Anal plug for faecal incontinence. Colorectal Dis 2001;3:323-7.

68. Lukacz ES, Segall MM, Wexner SD. Evaluation of an anal insert device for the conservative management of fecal incontinence. Dis Colon Rectum 2015;58:892-8.

69. Cameron JL. Current surgical therapy. St. Louis (MO); Elsevier Mosby; 2008.

70. Wald A. Fecal incontinence in adults. New Eng J Med 2007;356: 1648-55. 